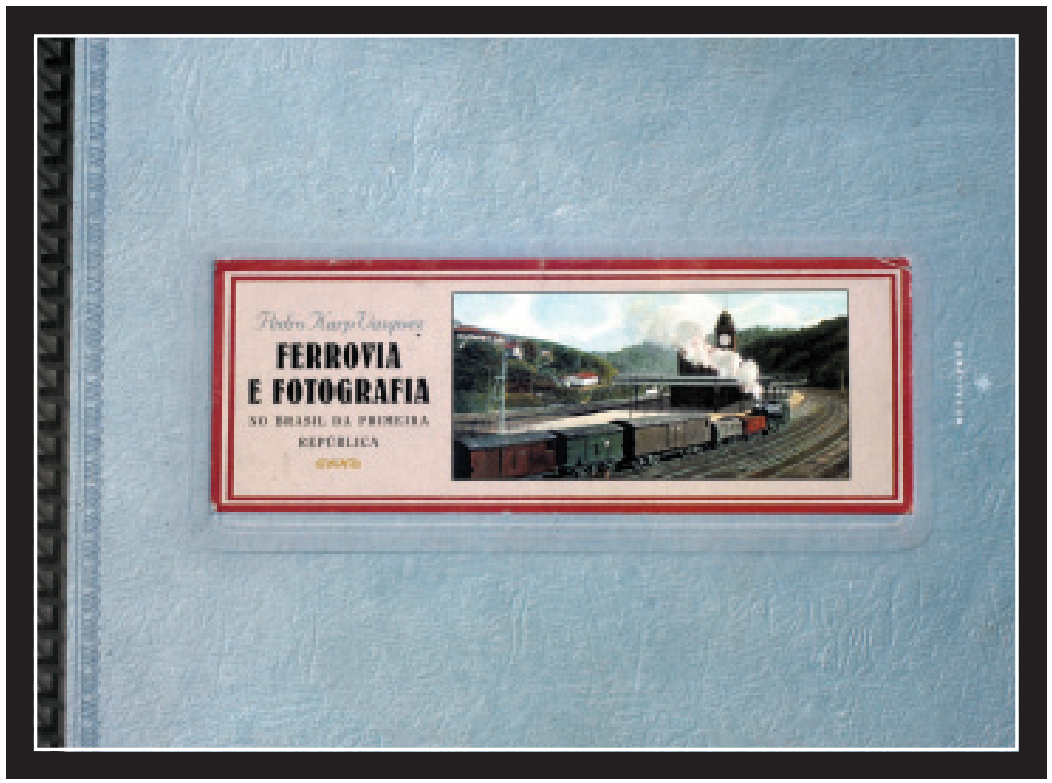

Ferrovia e Fotografia no Brasil da Primeira República, de Pedro Karp Vasquez. São Paulo: Metalivros, 2008. 287 p. 


\title{
Mais uma agradável viagem de trem
}

\author{
Paulo César Boni*
}

Walt Disney criou o personagem Mickey Mouse numa viagem de trem, em 1928. Os hoje famosos - e indispensáveis - livros de bolso (pocket books) foram concebidos numa estação ferroviária, em 1935, quando o editor inglês Allen Lane, ao retornar a Londres depois de uma visita à escritora Agatha Christie, procurou alguma coisa para ler na viagem e não encontrou nada que fosse pequeno, limpo e facilmente manuseável. Com citações como estas, Pedro Karp Vasquez salpica informação, humor e até ironias no primeiro capítulo do livro Ferrovia e Fotografia no Brasil da Primeira República, lançado em março deste ano pela Metalivros.

O livro é o segundo da trilogia sobre trem e fotografia. Seu antecedente, Nos trilhos do progresso: a ferrovia no Brasil Imperial vista pela fotografia, foi lançado pela mesma editora em 2007. Naquele, o autor reuniu, compilou e organizou a história da ferrovia no Brasil no período do Império. Neste, faz o mesmo com o período da Primeira República, inaugurado em 1889 e que se estendeu até o final de década de 30 do século XX. Nestas quatro décadas, a expansão da malha ferroviária foi tão intensa que, segundo o editor Ronaldo Graça Couto, “o país se colocou entre os detentores mundiais dos mais avançados e complexos sistemas ferroviários".

O grande mérito do livro, claro, está na reunião, organização espacial e cronológica da história da ferrovia, narrada por imagens, inclusive com a publicação de fotografias inéditas. Mas o livro tem alguns plus: a leveza do texto de Pedro Vasquez e a sutileza da contextualização histórica, tornando a leitura muito agradável e rica em informações. Ele não fala só sobre trens ou fotografias; pontua arte, cinema, literatura, economia, política e outras ciências na narrativa.

\footnotetext{
* Doutor em Ciências da Comunicação pela Universidade de São Paulo (ECA/USP). Coordenador do Mestrado em Comunicação da Universidade Estadual de Londrina.
} 
Para visualizar o livro - sem tê-lo em mãos - basta imaginá-lo dividido em quatro capítulos, depois acrescidos de álbuns fotográficos de acervos públicos e particulares e mais alguns apêndices. No primeiro capítulo - Embarcando - fala do surgimento do trem e da relação que a sociedade desenvolveu com ele. Lembra, na página 20, que "os trens e o universo ferroviário inspiraram escritores, artistas plásticos, compositores, roteiristas e diretores de cinema", e acha toda essa inspiração muito natural, afinal, "a gare ferroviária é um cenário espetacular; o trem foi o primeiro símbolo de modernidade na era industrial". E já no final do capítulo (página 24), antecipa parte do que o leitor irá encontrar pela frente: "a epopéia daqueles pioneiros do transporte ferroviário no período da República Velha que tiveram a coragem e a competência técnica para transformar sonhos em realidade, projetos em realizações", e vai além, dando uma estocada nenhum um pouco sutil nas políticas (ou na falta de) do desenvolvimento e da preservação do patrimônio histórico: "Legado este que, mesmo parcialmente destruído pela ignorância e incúria, está perenizado nas imagens aqui reproduzidas, testemunho do anseio de transformar uma terra em um país, uma referência geográfica numa nação, uma quimera numa realidade concreta."

Em trânsito, o título do segundo capítulo, destaca que, apesar do trem haver sido concebido para o transporte de cargas, sua invenção - assim como a do navio a vapor - propiciou uma nova categoria de seres humanos: os passageiros. Contudo, e desde sempre, o transporte de cargas foi a principal função do mundo ferroviário. Pedro Vasquez historia o surgimento dos trens e das estações ferroviárias e dos serviços e benefícios a eles incorporados no decorrer do tempo. Sanitários, salas de espera com cadeiras, cafeterias e lojinhas de conveniência nas estações; divisão por categorias, banheiros, cabines privativas, cabines dormitórios, vagão restaurante nos trens.

O autor narra, na página 30, uma experiência, no mínimo insólita de divisão de classes ocorrida na Bélgica: "Dentre os diferentes estratagemas concebidos para, literalmente 'manter cada qual no seu devido lugar', os belgas chegaram a conceber uma bizarra terceira classe merecedora de 
menção especial em virtude do caráter esdrúxulo, já que os passageiros eram obrigados a utilizar bancos abertos montados sobre o teto dos trens. Assim, nos dias de frio, quem já era duro no sentido figurado terminava a viagem verdadeiramente duro no sentido concreto: transformado em bloco de gelo. Este foi, por sinal, um dos fatores que levou ao término da terceira classe em diversos países, posto que poucos suportavam o desconforto durante os rigores do inverno."

Por outro lado, menos dramático, Pedro Vasquez arrisca dizer que as estações ferroviárias foram as primeiras experiências dos atuais shoppings centers. Fala da fama do vagão restaurante do luxuoso e lendário Expresso do Oriente, que percorria os $2.700 \mathrm{~km}$ entre Paris e Istambul. Este trem começou a circular em outubro de 1883 e inspirou muitos filmes e romances, inclusive o célebre romance policial de Agatha Christie: $O$ crime do Orient Express. Conta também que foi o inglês Thomas Cook quem primeiro teve a ideia de transformar viagens em lazer. Em 5 de julho de 1841, transportou um grupo de 570 pessoas entre a cidade de Leicester e Longborough, num percurso de apenas de 16 quilômetros. Estava inaugurado o turismo. Cook, aliás, foi dono da primeira agência de viagens do mundo.

Nestes dois primeiros capítulos, o livro não traz fotografias e sim gravuras, pinturas e logomarcas de empresas para ilustrar o texto. As fotografias passam a ser utilizadas a partir do terceiro capítulo, mas ainda de forma tímida. Contudo, são nos Álbuns - acervos fotográficos de diversos fotógrafos, mas todos voltados à ferroviaque elas exibem sua beleza estética e força documental.

No terceiro capítulo, Expansão ferroviária na República Velha, o autor narra a expansão da malha ferroviária. Para otimizar a abordagem e facilitar a compreensão do leitor frente à magnitude que os transportes ferroviários significaram para o país nesse período, optou por dividir o capítulo em subitens, um para cada região do país: Sudeste, Sul, Centro-Oeste, Nordeste e Norte. No item dedicado ao Sudeste, destacou a relação do café, então principal produto das exportações brasileiras, com a expansão da malha ferroviária nos então 
três principais estados produtores: Rio de Janeiro, São Paulo e Minas Gerais.

Como cidadão que assume publicamente seu orgulho de ser brasileiro, Pedro Vasquez rasgou elogios aos engenheiros brasileiros responsáveis pela construção de ferrovias em todo o país, pois superaram dificuldades muitas vezes maiores do que as enfrentadas pelos congêneres europeus. Na página 40, cita o caso da Estrada de Ferro Dom Pedro II, na Serra do Mar, no Paraná, em que "engenheiros brasileiros, como Antônio Rebouças, Cristiano Benedito Ottoni e João Teixeira Soares, ousaram ignorar parecer contrário e realizaram obras que permanecem até hoje como prodígios da engenharia ferroviária, despertando admiração e espanto e figurando como estudo de caso na história da construção de ferrovias".

No item da região Sul, o autor deixou falar mais alto sua paixão pela história e pela fotografia. Pouco falou de trens. Apenas comparou a importância do carvão para a expansão da malha ferroviária em Santa Catarina com a do café para a expansão da malha ferroviária no Sudeste. Ao começar a falar da atuação do megaempresário norte-americano Percival Farquhar na construção de ferrovias na região, a emoção falou mais forte: enveredou pela Guerra do Contestado (1912-1916). Uma lição de história! Para fechar o capítulo, destacou o papel do fotógrafo Claro Jansson como verdadeiro cronista visual do conflito. Uma lição da importância da fotografia para o resgate e preservação da história.

Para a região Centro-Oeste, Pedro Vasquez lembrou do projeto da Estrada de Ferro Noroeste do Brasil, que ambicionava ligar dois oceanos, o Atlântico e o Pacífico, mas malogrou. O destaque ferroviário na região ficou por conta da construção da estrada de Ferro Bauru-Cuiabá, iniciada em 1905. Três anos mais tarde, optou-se por estendê-la até Corumbá e, mais tarde, a Porto Esperança, na margem do rio Paraguai. Assim, com percurso total de 1.273 quilômetros, ela se tornou uma das mais importantes realizações ferroviárias brasileiras.

O autor destaca a importância da construção desta ferrovia também para a ocupação e desenvolvimento do oeste do estado de São Paulo, 
onde, inclusive, houve pesados conflitos com os índios kaingangs, que habitavam a região. O historiador Paulo Roberto Cimo Queiroz, citado pelo autor na página 58, lembra que "foi a comoção pública em relação ao conflito que ocasionou a criação do Serviços de Proteção aos Índios (embrião da atual Funai), em 1910".

Um produto também foi o grande impulsionador da malha ferroviária no Nordeste: a cana-de-açúcar. Ela chegou a exercer tamanha importância econômica na região que Pedro Vasquez não achou exagerado afirmar, na página 59, que "as estradas de ferro ajustavam os percursos para atender aos grandes engenhos ou usinas". Nesse item, o da região Nordeste, o autor destaca também que lá o inimigo foi outro: o cangaço. Os cangaceiros impediam ou atrasavam a construção de estradas de ferro e, não raro, extorquiam dinheiro das construtoras para permitir o andamento das obras. Comparada à das outras regiões até agora vistas, a malha ferroviária dessa região é relativamente pequena.

A borracha teria sido o grande motivador de algumas tentativas de construir estradas de ferro na região Norte. Dentre elas, a mais famosa ferrovia brasileira: a Estrada de Ferro Madeira-Mamoré. Com 366 quilômetros de extensão, construída entre 1907 e 1912, ligando as cidades de Porto Velho e Guajará-Mirim, ela não se tornou a mais famosa por sua importância, mas sim por seus erros. Como havia feito na narração da região Sul, Pedro Vasquez novamente se deixou absorver pela história e pela fotografia. Narrou com riqueza de detalhes a concepção da MadeiraMamoré, a participação de Percival Farquhar e suas estratégias para a construção (e, claro, para ganhar dinheiro) da estrada de ferro e a descoberta de um tesouro imagético: o acervo do fotógrafo oficial da construção da Estrada de Ferro Madeira-Mamoré, o norte-americano Dana Merrill. Duas novas lições: uma de história, outra da importância documental da fotografia.

Deste episódio, quero reproduzir dois trechos do texto de Pedro Karp Vasquez, ambos na página 66. O primeiro diz: "Há quem pense que vasculhar velhos baús e antigos arquivos é ocupação vã e ociosa, sem utilidade prática para o tempo presente. Isso é desconhecer inteiramente 
as múltiplas possibilidades contemporâneas que se descortinam a cada nova descoberta dos pesquisadores e historiadores, não só no âmbito mais restrito e erudito da universidade como em diferentes áreas da vida cotidiana." E, na sequência imediata, justifica o porquê dessa fala. "Exemplo interessantíssimo de utilização prática de arquivos do passado ocorreu com o legado do fotógrafo norte-americano Dana Merrill relativo à construção da Estrada de Ferro Madeira-Mamoré, que permaneceu no olvido por quase meio século, antes de ser resgatado em 1956 graças à ação conjunta do fotógrafo Ari André e do engenheiro, jornalista, historiador e sertanista Manoel Rodrigues Ferreira."

Só para encerrar a história, hoje, graças à lucidez de algumas pessoas, 198 fotografias estão recuperadas, acervadas, preservadas e disponibilizadas para consulta no Museu Paulista da Universidade de São Paulo, uma grande vitória da memória brasileira. Porém, infelizmente, é preciso dizer que 198 fotografias representam apenas $10 \%$ da produção de Dana Merrill, referente à construção da Estrada de Ferro MadeiraMamoré. Os outros $90 \%$ foram perdidos.

No quarto e último capítulo do livro, Engenheiro, o autor presta uma justa homenagem ao engenheiro João Teixeira Soares, a quem ele chamou de "gigante do universo ferroviário brasileiro". Nascido a 25 de outubro de 1848, Teixeira Soares, segundo relato de seu bisneto Eduardo Soares de Sampaio Filho, tomou gosto por trens e ferrovias ainda aos cinco anos de idade, quando, em 30 de abril de 1854, seu pai leu em voz alta a notícia do Jornal do Commercio dando conta da inauguração da primeira ferrovia brasileira.

Engenheiro ousado e empreendedor destemido, Teixeira Soares tem seu nome ligado à construção de algumas das mais importantes ferrovias brasileiras, dentre as quais a Curitiba-Paranaguá, no Paraná, a Estrada de Ferro do Corcovado, no Rio de Janeiro, e a Itararé (SP)Santa Maria (RS). Nesta última, apesar de todos os esforços, foi obrigado a vender a concessão para ninguém menos que Percival Farquhar. Depois desse revés, construiu a Estrada de Ferro Vitória-Minas (EFVM). As fotografias do engenheiro, em momentos da intimidade familiar e 
profissionais que ilustram o capítulo, foram todas tomadas pelo fotógrafo Octávio de Oliveira Castro. Pedro Vasquez relata que Teixeira Soares morreu em 27 de agosto de 1927, em Paris, onde estava a trabalho. "Foi um empreendedor até o último dia de vida", destaca.

Na sequência, em Álbuns, o livro traz preciosidades: fotografias de acervos dedicados às estradas de ferro, em mãos de instituições públicas ou de colecionadores particulares. O primeiro álbum é do Museu Paulista da Universidade de São Paulo, com 51 fotografias do fotógrafo norte-americano Dana Merrill, todas referentes à Estrada de Ferro Madeira-Mamoré. Em seguida vem o acervo de Jandira Jansson, com 29 fotografias de Claro Jansson, a maioria delas referente à construção da Estrada de Ferro de Santa Catarina, mas com algumas tomadas em Itararé (SP), Sengés (PR) e da construção da ponte sobre o rio Uruguai, na divisa dos estados de Santa Catarina e Rio Grande do Sul. O terceiro álbum traz 18 fotografias, todas de "autor não identificado", pertencentes ao Museu da Companhia Paulista de Estradas de Ferro como parte do Acervo da Companhia Mogiana. A Coleção Rubens Fernandes Júnior traz 47 fotografias e cartões postais (normalmente uma fotografia transformada em cartão postal) de diferentes estações, túneis e viadutos de diversas estradas de ferro do país. Finalmente, a Coleção Luiz e Lúcia David de Sanson, que traz 30 fotografias, todas tomadas pelo fotógrafo Octávio de Oliveira Castro, boa parte delas retratando o engenheiro João Teixeira Soares e membros de sua família. Mas há também imagens da construção de estradas de ferro, notadamente da Curitiba-Paranaguá, com destaque para algumas pontes de surpreendente engenharia, construídas na Serra do Mar.

Dia 4 de março deste ano, recebi um e-mail do Pedro Karp Vasquez, no qual ele anexava o convite para o lançamento do livro, dia 6 de março, numa livraria do Rio de Janeiro. A mensagem do e-mail era curta, e simples: "Paulo, lá vai mais um trem." Depois de me deliciar com os textos e imagens das 287 páginas do livro, respondi com a seguinte mensagem: "Pois que venham outros, Pedro." 